\title{
Energy Transfer from lons to Electrons and the Coulomb Logarithm
}

\author{
J. Rand McNally, Jr.
}




\section{DISCLAIMER}

This report was prepared as an account of work sponsored by an agency of the United States Government. Neither the United States Government nor any agency Thereof, nor any of their employees, makes any warranty, express or implied, or assumes any legal liability or responsibility for the accuracy, completeness, or usefulness of any information, apparatus, product, or process disclosed, or represents that its use would not infringe privately owned rights. Reference herein to any specific commercial product, process, or service by trade name, trademark, manufacturer, or otherwise does not necessarily constitute or imply its endorsement, recommendation, or favoring by the United States Government or any agency thereof. The views and opinions of authors expressed herein do not necessarily state or reflect those of the United States Government or any agency thereof. 


\section{DISCLAIMER}

Portions of this document may be illegible in electronic image products. Images are produced from the best available original document. 


\section{Printed in the United States of America. Available from National Technical Information Service U.S. Department of Commerce 5285 Port Royal Road, Springfield, Virginia 22161 \\ Price: Printed Copy $\$ 4.00$; Microfiche $\$ 3.00$}

This report was prepared as an account of work sponsored by the United States Government. Neither the United States nor the Energy Research and Development Administration/United States Nuclear Regulatory Commission, nor any of their employees, nor any of their contractors, subcontractors, or their employees, makes any warranty, express or implied, or assumes any legal liability or responsibility for the accuracy, completeness or usefulness of any information, apparatus, product or process disclosed, or represents that its use would not infringe privately owned rights. 
ORNL/TM-5803

Contract No: W-7405-eng-26

FUSION ENERGY DIVISION

ENERGY TRANSFER FROM IONS TO ELECTRONS AND THE COULOMB LOGARITHM

J. Rand McNally, Jr.

Date Published - September 1977

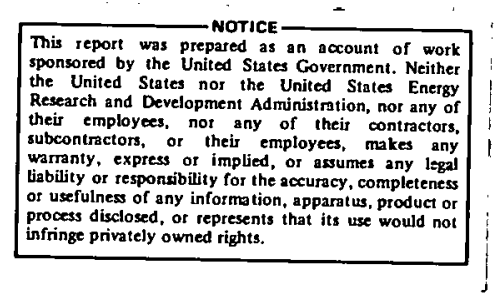

Prepared by the

OAK RIDGE NATIONAL LABORATORY

Oak Ridge, Tennessee 37830

operated by

UNION CARBIDE CORPORATION

for the

ENERGY RESEARCH AND DEVELOPMENT ADMINISTRATION

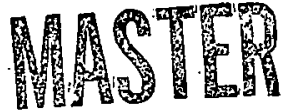


ENERGY TRANSFER FROM IONS TO ELECTRONS AND THE COULOMB LOGARITHM*

J. Rand McNally, Jr. Fusion Energy Division

Oak Ridge National Laboratory

Oak Ridge, TN 37830

United States of America

\begin{abstract}
Application of Chandrasekhar's stellar approach to plasmas reveals the importance of nondominant terms in both the energy transfer from ions to electrons and the form of the Coulomb logarithm. Curves illustrate the role of dominant and nondominant terms in the neighborhood of $v_{e} \sim v_{i}$.
\end{abstract}

‡ Research sponsored by the Energy Research and Development Administration under contract with Union Carbide Corporation. 
ENERGY TRANSFER FROM IONS TO ELECTRONS AND THE COULOMB LOGARITHM

The role of the Coulomb logarithm in the energy transfer from a test ion to field electrons is discussed in the framework of Chandrasekhar's approach to the star problem. The inclusion of nondominant terms permits test ions to lose energy to somewhat faster electrons (e.g., up to about $v_{e} \sim 10-20 v_{j}$ ), although at a very greatly reduced rate per electron compared to the dominant terms used for $v_{e}<v_{i}$; however, the two sets of energy losses are comparable for a Maxwellian sea of electrons. The effects of magnetic and electric fields on the energy loss terms are discussed briefly.

Chandrasekhar has evaluated the coefficient of dynamical friction $\Sigma \Delta v_{11}[1]$ and the energy dispersion [2] for a test star interacting with field stars. The energy loss rate is $m_{i} v_{i} \Sigma \Delta v_{11} / \Delta t$. His approach has been applied to the plasma physics case by numerous individuals [3]. By averaging Chandrasekhar's collision energy transfer term [2] $\Delta E$ (instead of $\Delta E^{2}$, which leads to energy dispersion) over the collision frequency for the plasma case, one can obtain the net energy transfer rate, i.e., power gain-power loss. This has important ramifications in the plasma case involving a test ion and field electrons since the nondominant contribution becomes quite significant compared with the dominant contribution because of the large differences in masses and velocities of ions and electrons.

Chandrasekhar's binary collision energy transfer term [2] expressed in plasma notation for a test ion in field electrons is

$$
\Delta E_{i}=-\frac{2 m_{e} m_{i}}{m_{e}+m_{i}} V V_{G} \cos (\phi-\psi) \cos \psi \cos i \text {, }
$$


where $V$ is the relative velocity, $V_{G}$ is the velocity of the center of mass, $\phi$ is the angle which $\vec{V}$ makes with the projection of $\vec{V}_{G}$ on the orbital plane, $i$ is the angle between the projection of $\vec{V}_{G}$ on the orbital plane and $\vec{V}_{G}$, and $\psi$ is related to the impact parameter b by $\cos \psi=\frac{1}{\sqrt{\frac{b^{2} m_{e}^{2} m_{i}^{2} v^{4}}{z^{2} e^{4}\left(m_{e}+m_{i}\right)^{2}}+1}}$

The expression for power transfer to Maxwellian electrons is then $\frac{d E_{i}}{d t}=\int \Delta E_{i} 2 \pi b d b N_{e}\left(v_{e}\right) \frac{\sin \theta d \theta d \Phi}{4 \pi} v d v_{e} \frac{d \theta}{2 \pi} ;$

assuming spherical symmetry for the electron velocities. This leads to $\frac{d E_{i}}{d t}=-\frac{\pi\left(m_{e}+m_{j}\right) z^{2} e^{4}}{2 m_{e} m_{i} v_{i}} \int_{0}^{\infty} \frac{N_{e}\left(v_{e}\right) j-}{v_{e}} d v_{e}$,

where

$N_{e}\left(v_{e}\right)=\frac{\sqrt{2} m_{e}^{3 / 2} n_{e} v_{e}^{2}}{\sqrt{\pi}\left(k T_{e}\right)^{3 / 2}} e^{-m_{e} v_{e}^{2} / 2 k T_{e}}$

for a Maxwellian. J- for the net power transfer case differs slightly but importantly from Chandrasekhar's $\mathrm{J}$ for the power loss case [1]. In other words,

$$
J=\int_{\left|v_{i}-v_{e}\right|}^{v_{i}+v_{e}}\left(\frac{m_{i}-m_{e}}{m_{i}+m_{e}}+\frac{v_{i}^{2}-v_{e}^{2}}{v^{2}}\right) \ln \left(1+q^{2} v^{4}\right) d v
$$

and 
$J=\int_{\left|v_{i}-v_{e}\right|}^{v_{i}+v_{e}}\left(1+\frac{v_{i}^{2}-v_{e}^{2}}{v^{2}}\right) \ln \left(1+q^{2} v^{4}\right) d v$,

where $q=\lambda_{D} m_{e} m_{j} / Z e^{2}\left(m_{e}+m_{j}\right)$. Gryzinski [4] gives an equivalent expression for $\mathrm{J}$ -

Under most conditions of practical interest in plasma physics, the $q^{2} v^{4}$ term is large compared with unity except for $v_{e}$ very close to $v_{i}$. (Pellet fusion and other partially or fully degenerate plasmas have very small $q^{2} v^{4}$ terms for $v_{e} \leq v_{i}$, and both $q^{2} v^{4}$ and 1 are important. Thus, Gryzinski [4] obtains an energy loss rate four times larger than that of Fermi and Teller [5] as a result of using all the degenerate electrons.) Except for the narrow range of $v_{e}$ very close to $v_{i}$ (which does not exhibit any blowup), one can obtain approximately for the dynamical friction coefficient (see [l]) expressed in terms of $\mathrm{J}$ :

$$
\begin{array}{ll}
J_{<}=8 v_{e} \ln q\left(v_{i}^{2}-v_{e}^{2}\right) & \text { for } v_{e}<v_{i}, \\
J_{=}=4 v_{i} \ln \left(4 q v_{i}^{2}\right)-8 v_{i} & \text { for } v_{e}=v_{i},
\end{array}
$$

and

$$
J_{>} \simeq 8 v_{e} \ln \frac{v_{c}+v_{i}}{v_{c}-v_{i}}-16 v_{i} \quad \text { for } v_{e}>v_{i} \text {. }
$$

Similarly, for the energy transfer coefficient one obtains for $J^{-}$

$$
\begin{aligned}
& J_{<} \simeq \frac{1}{m_{e}+m_{i}}\left\{8 m_{i} v_{e} \operatorname{lnq}\left(v_{i}^{2}-v_{e}^{2}\right)-8 m_{e} v_{i} \ln \frac{v_{i}+v_{e}}{v_{i}-v_{e}}+16 m_{e} v_{e}\right\}, \\
& J_{=}=\frac{\left(m_{i}-m_{e}\right) v_{i}}{m_{e}+m_{i}}\left[4 \ln \left(q v_{i}^{2}\right)-8\right],
\end{aligned}
$$


and

$J_{>} \simeq \frac{1}{m_{e}+m_{j}}\left\{8 m_{i} v_{e} \ln \frac{v_{e}+v_{i}}{v_{e}-v_{i}}-4 m_{e} v_{i} \operatorname{lnq}\left(v_{e}^{2}-v_{i}^{2}\right)-16 m_{i} v_{i}\right\}$ :

Chandrasekhar states that in the dominant term approximation $J_{>} \rightarrow 0$ for $v_{e}>v_{i}$, and he concludes that one finds "the remarkable result that to a sufficient accuracy only stars with velocities less than the one under consideration contribute" to the dynamical friction [1]. This argument is not valid in the plasma test ion field electron case, because a fairly significant ion energy loss arises from the many electrons somewhat faster than the test ion because $N\left(v_{e}\right) \propto v_{e}^{2}$ for $v_{e}^{2}<$ $0.1 \overline{v_{e}^{2}}$. Less than $\sqrt{\frac{16}{\pi}}\left[\frac{m_{e} E_{i}}{m_{j} k T_{e}}\right]^{3 / 2}$ of the electrons have $v_{e} \leq v_{i}$ for $E_{i}<0.1\left[\frac{m_{i}}{m_{e}}\right] k T_{e}$.

As an example, the case $q=\lambda_{D} \mathrm{~m}_{\mathrm{e}} / \mathrm{Ze}^{2}=3 \times 10^{-11}, \mathrm{~T}_{\mathrm{e}}=10 \mathrm{keV}$, and $v_{j}=2 \times 10^{8} \mathrm{~cm} / \mathrm{sec}\left(E_{p} \simeq 21 \mathrm{keV}, E_{d} \simeq 42 \mathrm{keV}\right.$, or $\left.E_{t} \simeq 63 \mathrm{keV}\right): 1$ eads to the results shown in Fig. 1, which includes the nondominant as well as the dominant terms in $\mathrm{J}$ given earlier. "The total area under the curve represents the energy loss rate of a test ion to a Maxwellian sea of electrons at $T_{e} \sim 10 \mathrm{keV}$. Note that the area for $v_{e} \geq v_{i}$ is almost equal to the area below $v_{e}=v_{i}$, whereas with dominant terms only, $j$ is taken to be zero for $v_{e}>v_{j}$. Thus, nondominant terms are important in the plasma case.

Consider now the velocity "breakpoint" $\left(v_{\mathrm{eBP}}\right)$ in energy transfer: for $v_{e}>v_{e B P}$ the test ion gains energy from the electrons, whereas below $v_{e}<v_{e B P}$ the ion loses energy to the electrons. To evaluate this, one sets $J_{>}^{\infty}=0$ because only the fast electrons can heat the ions faster 
than they cool. On expanding the first term of $J_{>}^{\prime}$ one has

$$
\begin{aligned}
0= & m_{i} v_{e}\left[\frac{v_{i}}{v_{e}}-\frac{v_{i}^{2}}{2 v_{e}{ }^{2}}+\frac{v_{i}^{3}}{3 v_{e}^{3}}+\ldots-\left(-\frac{v_{i}}{v_{e}}-\frac{v_{i}^{2}}{2 v_{e}^{2}}-\frac{v_{i}^{3}}{3 v_{e}^{3}}-\ldots\right)\right] \\
& -\frac{1}{2} m_{e} v_{i} \ln \left(q v_{e}{ }^{2}\right)-2 m_{i} v_{i},
\end{aligned}
$$

and one obtains

$0 \simeq \frac{2}{3} m_{i} v_{i} \frac{v_{i}^{2}}{v_{e}^{2}}-\frac{1}{2} m_{e} v_{i} \ln \left(q v_{e}^{2}\right)$.

This gives

$v_{\mathrm{eBP}} / v_{i}=\sqrt{\frac{4 m_{i}}{3 m_{e}{ }^{l n q v_{e}^{2}}}}$

$\approx \sqrt{\frac{m_{i}}{15 m_{e}}}=\left\{\begin{array}{l}11.1 \text { for protons } \\ 15.7 \text { for deuterons } \\ 19.2 \text { for tritons }\end{array}\right\}$ for $\ln \left(q_{e}{ }^{2}\right)=20$

It should be noted that the energy loss per electron at $v_{e}=10 v_{j}$ is $21 / 100$ as large as shown on Fig. 1 as compared with electrons at $v_{e} \leqslant v_{i}$, since $N\left(v_{e}\right) \propto v_{e}^{2}$ for $v_{e}^{2}$ well below the value $2 k T e / m_{e}$.

Figure 2 yives the average energy loss rates per electron from a test ion to an electron of velocity $v_{e}$, thus showing the relative importance of the dominant terms compared to the nondominant terms.

Since most of the energy loss by the test ion occurs in the neighborhood of $v_{e} \sim v_{j}$, the energy loss is dominated by $v$ in this region of velocity space and the coulomb logarithm term is more nearly $\ell n \Lambda_{e j} \sim$ $\ln \left(q v_{i}^{2}\right)$; however, for electrons heating the test ion one has $\ell n \Lambda e i$ ? 
$\ln \left(\overline{q v_{e}^{2}}\right)$. Making the small $v_{e}$ approximation $\left[j_{<} \simeq \frac{8 m_{j} v_{e}}{m_{i}+m_{e}} \ln \left(q v_{i}{ }^{2}\right)\right]$ for $N\left(v_{e}\right)=n_{e} \frac{\sqrt{2} m_{e} e^{3 / 2} v_{e}^{2}}{\sqrt{\pi}\left(k T_{e}\right)^{3 / 2}} e^{-m_{e} v^{2} e^{2 / 2 k T} e}$,

and integrating from $v_{e}=0$ to $v_{e}=v_{i}$ (the exponential is near unity for $\left.T_{j} \sim T_{e}\right)$, one obtains in the dominant approximation the energy loss $\frac{d E_{i}}{d t} \simeq-\frac{8 \sqrt{2 \pi} n_{e} z^{2} e^{4} \sqrt{m_{e}} E_{i}}{3 m_{j}\left(k T_{e}\right)^{3 / 2}} \cdot \ln \left(\frac{\lambda_{D} m_{e} v_{i}^{2}}{Z e^{2}}\right)$.

This agrees with the classical loss expression [6] except for $\Lambda_{i e}=$ $\lambda_{D} m_{e} v_{i}{ }^{2} / Z e^{2}$ instead of $\Lambda_{e i}=\lambda_{D} 3 k T_{e} / Z e^{2}$. Similarly, for large values of $v_{e}$ one has

$J_{>} \simeq-\frac{8 m_{e} v_{i}}{m_{e}+m_{i}} \ln \left(q v_{e}^{2}\right)$,

leading to approximately (taking $v_{e}^{2} \sim \overline{v_{e}^{2}}=3 k T_{e} / m_{e}$ )

$\frac{d E_{i}}{d t} \simeq+\frac{8 \sqrt{2 \pi} n_{e} z^{2} e^{4} \sqrt{m} E_{e}}{3 m_{i}\left(k T_{e}\right)^{3 / 2}}$ en $\frac{\lambda_{D} 3 k T e}{Z e^{2}}$,

which agrees with the classical heating expression in Ref. [6]. When evaluating numerically the exact integrals for $\frac{d E}{d t}$, one finds essentially numerical agreement (because of the contribution from the nondominant terms near $v_{e} \geq v_{j}$ ) with the classical form:

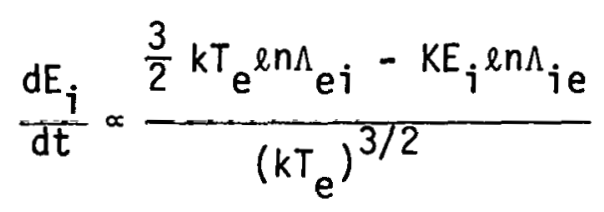
(numerically) 


$$
\propto \frac{\left(\frac{3}{2} k T_{e}-E_{j}\right) \ln \Lambda}{e i}, \quad \text { (Ref. [6]) }
$$

where capital $K$ is a numerical factor and $K \ell n \Lambda_{i e} \sim \ell n \Lambda_{e i}$ in the numerical cases studied. Thus, in the absence of energy source and radiation loss terms, $T_{i} \rightarrow T_{e}$ at equilibrium.

The qualitative effect of magnetic field cutoffs of the maximum impact parameter has been previously considered [7]; if $v_{e} / \omega_{c e}<\lambda_{D}$, the coulomb logarithm is reduced for the ion energy loss. Thus, to correct quantitatively for magnetic field effects on the Coulomb logarithm, the exact expression for the energy transfer rate given in this note must be evaluated with the Debye length $\lambda_{D}=\lambda_{D}$ or $\sim v_{e} / \omega_{c e}$, whichever is smaller. This selectively reduces the ion energy loss term (small $v_{e}$ case) compared with the ion energy gain case (large $v_{e}$ ), and at equilibrium $T_{\mathbf{j}}>T_{\mathbf{e}}$ for a Maxwellian electron distribution even in the absence of other energy gain or loss terms. What this means in a physical sense is that the ions gain a slight amount of energy at the expense of the electrons in the case of a strong magnetic field. There is no net transfer of energy from the magnetic field. The work of Montgomery et al. [9] treats the effect of the magnetic field on the Coulomb logarithm only for the electron-electron case. This leads to a much smaller correction due to the higher electron velocities compared to the test ion plasma electron case $\left(v_{e} / \omega_{c e}<\lambda_{D}\right)$.

Some years ago the author considered several other ways of depleting the cold electron portion of the Maxwellian electron distribution, i.e., in the region of $v_{e} \leq v_{i}$. Among these prospects was the effect of electric and magnetic fields in a plasma and especially in a plasma 
such as the Ion-Layer [8] where $B$ is reduced from $B_{0}$. $A 11$ electrons (as wel1 as ions) pick up a mean drift energy $m_{e} v_{d}{ }^{2}=m_{e} c^{2} \xi_{\perp}{ }^{2} / B^{2}$ which may promote a significant number of the electrons out of the cold tail corresponding to $v_{e} \leq v_{f}$ and into the region $v_{e}>v_{f}$, where their individual stopping power is greatly reduced. Figure 2 illustrates the gross reduction of the energy loss if an electron is promoted from $v_{e}<v_{i}$ to $v_{e}>v_{i}$. This depletion effect is currently being investigated independently elsewhere [10]; whether an ion velocity increase will wash out any significant effect merits careful study.

Futch et al. [11] observed an approximately 5\% depletion of cold electrons via ordinary Coulomb collision processes evaluated on the bas is of Fokker-Planck analysis; however, they used $\ell n \Lambda$ as a constant (as do Trubnikov [12] and Fowler and Rankin [13]) and extracted it from the velocity integral.

Sivukhin [14] recognized the relative velocity dependence of the Coulomb logarithm but treated it as a constant depending on the average velocity of the special classes he considered. This is a reasonably valid approximation when $v_{\text {test }} \gg v_{\text {field }}$ but not in the particular. case we treat here, since for test ions losing energy to that class of electrons having $v_{e} \leqslant v_{i}$ the Coulomb logarithm is significantly different from the case of the much faster electrons in the plasma heating the test ions $\left(v_{\mathrm{e}} \gg v_{j}\right)$. Sivukhin's basic equation (3.9) agrees essentially with our analysis of Chandrasekhar since for a test ion of charge $Z$ interacting with electrons

$\left(\frac{d E}{d t}\right)_{S}=-\frac{4 \pi Z^{2} e^{4}}{\mu} \int \frac{L}{v^{3}}\left(\vec{V}_{G} \cdot \vec{v}\right) f\left(v_{e}\right) d v_{e}$, 
where $L$ is the Coulomb logarithm. This is to be compared with the Chandrasekhar form

$$
\begin{aligned}
\left(\frac{d E}{d t}\right)_{C h} & =-\frac{\pi z^{2} e^{4}}{2 \mu v_{i}} \int \frac{f_{e}\left(v_{e}\right) J-d v_{e}}{v_{e}} \\
& =-\frac{\pi z^{2} e^{4}}{u v_{i}} \iint\left(\frac{m_{i}-m_{e}}{m_{i}+m_{e}}+\frac{v_{i}^{2}-v_{e}^{2}}{v^{2}}\right) \ln \left(1+q^{2} v^{4}\right)^{\frac{1}{2}} d v \frac{f_{e}\left(v_{e}\right) d v_{e}}{v_{e}}
\end{aligned}
$$

and taking $L \sim \ln \left(1+q^{2} V^{4}\right)^{\frac{1}{2}}$ and following Chandrasekhar [2]

$$
\left(\frac{d E}{d t}\right)_{C h}=-\frac{\pi Z^{2} e^{4}}{u v_{i}} \iint \frac{2 L}{v_{e} v^{2}}\left(\vec{v}_{G} \cdot \vec{v}\right) d V f_{e}\left(v_{e}\right) d v_{e} \text {. }
$$

Again, from Ref. [2]

$$
\left(\frac{d E}{d t}\right)_{C h}=-\frac{\pi z^{2} e^{1}}{\mu v_{i}} \iint \frac{L}{v_{e} v^{3}}\left(\vec{v}_{G} \cdot \vec{v}\right) 2 v_{j} \cdot v_{e} \sin \theta d \theta f_{e}\left(v_{e}\right) d v_{e}
$$

or

$$
\left(\frac{d E}{d t}\right)_{C h}=-\frac{4 \pi z^{2} e^{4}}{\mu} \int \frac{L\left(\vec{V}_{G} \cdot \vec{V}\right)}{v^{3}} f\left(v_{e}\right) d v_{e} \text {, }
$$

which agrees with the Sivukhin formula.

The presence of nuclear energy reaction products heating the ions preferentially (via nuclear elastic collisions if $T_{e}$ is $\geq 100 \mathrm{keV}$ ) and radiation losses cooling the electrons would lead to a still larger discrepancy between $T_{j}$ and $T_{e}$, especially if the cold electron tail is depleted.

A detailed Fokker-Planck analysis appears appropriate to evaluate the effect of both magnetic and electric fields on equilibrium and on possible perturbations of the ion and electron distributions. Should the 
stopping power of the cold electrons be significantly reduced, the cleaner advanced fusion fuels may be found to be even more technologically feasible [15]. 


\section{REFERENCES}

[1] CHANDRASEKHAR, S., Astrophys. J. 97 (1943) 255.

[2] CHANDRASEKHAR, S., Astrophys. J. 94 (1941) 511.

[3] SPITZER, L., Jr., Physics of Fully Ionized Gases, Interscience Publishers, New York (1962).

[4] GRYZIŃSKI, M., Phys. Rev. 107 (1957) 1471.

[5] FERMI, E., TELLER, E., Phys. Rev. 72 (1947) 399.

[6] GLASSTONE, S., LOVBERG, R. H., Controlled Thermonuclear Reactions, D. Van Nostrand Co., Inc., Princeton, New Jersey (1960). See Eq. 4.61.

[7] MCNALLY, J. RAND, JR., Nucl. Fusion 15 (1975) 344.

[8] MCNALLY, J. RAND, JR., Nucl. Fusion 12 (1972) 265.

[9] MONTGOMERY, D., JOYCE, G., TURNER, L., Phys. Fluids 17 (1974) 2201.

[10] MILLER, R. A., Fusion Energy Corporation, personal communication (1976).

[11] FUTCH, A. H., JR., HOLDREN, J. P., KILLEEN, J., and MIRIN, A. A., Plasma Phys. 14 (1972) 211; USAEC Report UCRL-73226 (1971).

[12] TRUBnikOV, B. A., Reviews of Plasma Physics I (1965) 105.

[13] FOWLER, T. K., RANKIN, M., Plasma Phys. C121 (1966) 121.

[14] SIVUKHIN, D. V., Coulomb Collisions in a Fully Ionized Plasma, Reviews of Plasma Physics $\underline{4}$ (1966) 93.

[15] MCNALLY, J. RAND, JR., Nucl. Fusion 11 (1971) 187; ORNL/TM-3233 (1971); 6th IEEE Symp. on Engineering Problems of Fusion Research (1976) 1012; Bu11. Am. Phys. Soc. 21 (1976) 1163. Prospects include $\mathrm{DD}, \mathrm{D}^{3} \mathrm{He},{ }^{3} \mathrm{He}{ }^{3} \mathrm{He}, p^{6} \mathrm{Li}, D^{6} \mathrm{Li}, \mathrm{p}^{9} \mathrm{Be}$, and $p^{11} \mathrm{~B}$. 
Figure Captions

Fig. 1. Relative energy loss rate of a test ion to electrons of various $v_{e}$ in a Maxwellian distribution at $T_{e}=10 \mathrm{kev}, v_{i}=2 \times 10^{8}$ $\mathrm{cm} / \mathrm{sec}, \mathrm{n}_{\mathrm{e}}=10^{14} \mathrm{e} / \mathrm{cm}^{3}$, and $\mathrm{q}=3 \times 10^{-11} \mathrm{sec}^{2} / \mathrm{cm}^{2}$.

Fig. 2. Electron velocity dependence of the test ion energy loss rate per electron in a plasma at $n_{e}=10^{14} \mathrm{e} / \mathrm{cm}^{3}, T_{e}=10 \mathrm{keV}$, $q=3 \times 10^{-11} \mathrm{sec}^{2} / \mathrm{cm}^{2}$, and test ion velocity $v_{i}=2 \times 10^{8} \mathrm{~cm} / \mathrm{sec}$. 


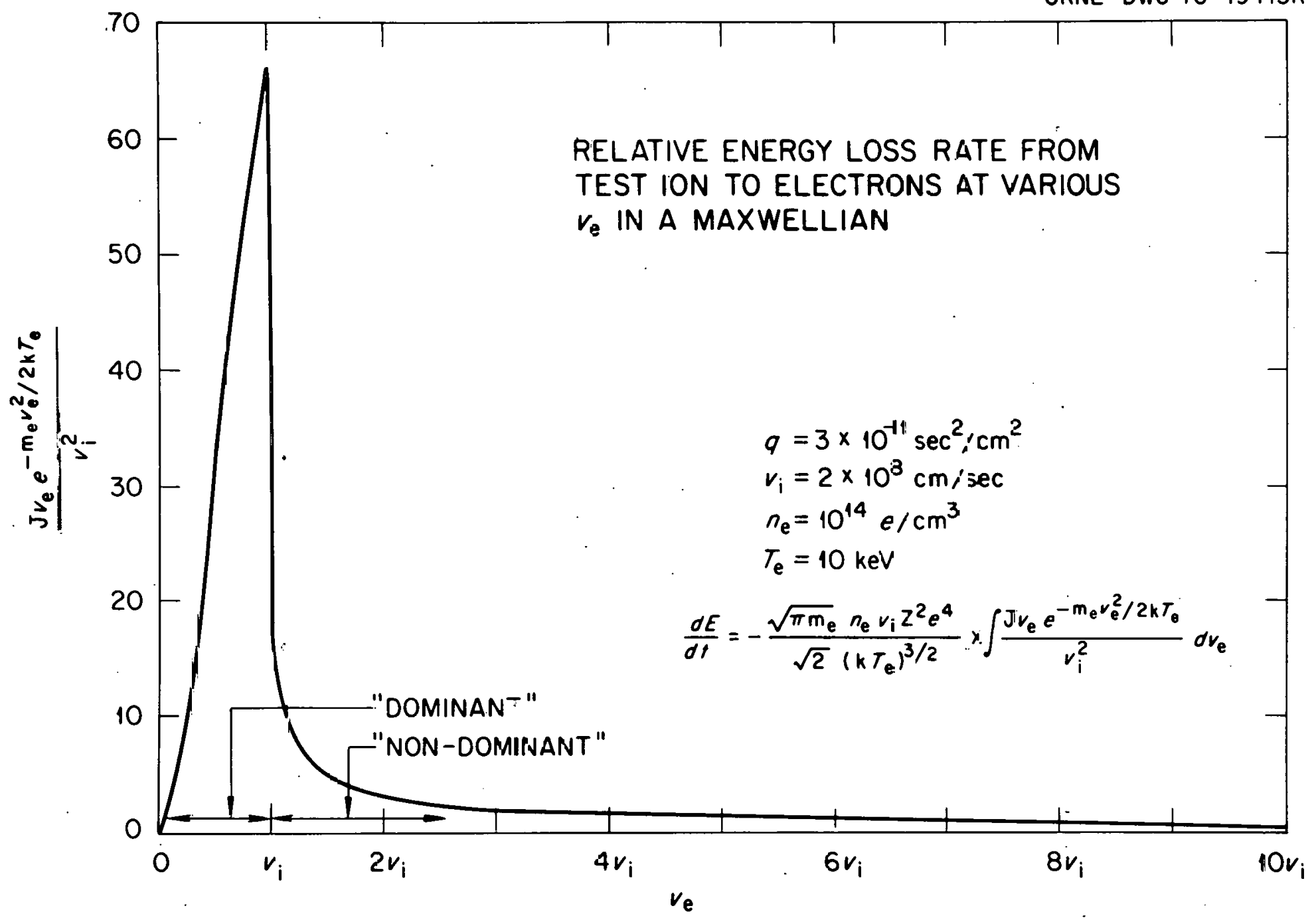

Figure 1 


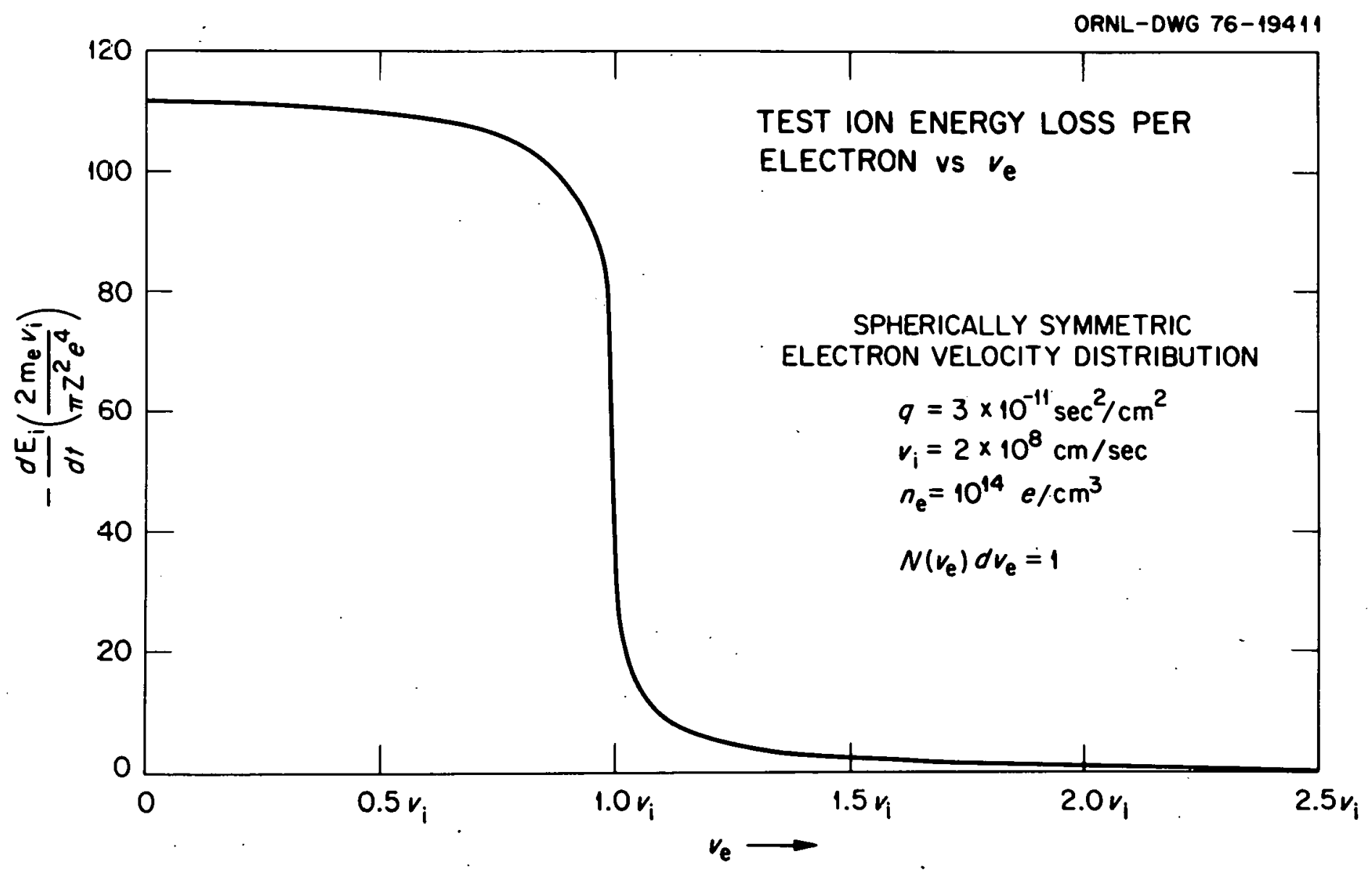

Figure 2 


\section{THIS PAGE \\ WAS INTENTIONALLY \\ LEFT BLANK}


ORNL/TM-5803

\section{INTERNAL DISTRIBUTION}

1. J. D. Callen

2. J. F. Clarke

3. R. A. Dory

4. G. G. Kelley

5. 0. B. Morgan

6. M. W. Rosenthal

7-31. J. R. McNally, Jr.

32-34. Laboratory Records Department

35. Laboratory Records, ORNL - RC

36. $Y-12$ Document Reference Section

37-38. Central Research Library.

39. Fusion Energy Division Library

40. Fusion Energy Division Reports Office

41. ORNL Patent Office

\section{EXTERNAL DISTRIBUTION}

42. Plasma Physics Library, Plasma Physics Laboratory, Princeton Univ., Forrestal Campus, P.0. Box 451, Princeton, NJ 08540

43. Controlled Thermonuclear Research Library, Lawrence Livermore Laboratory, P.0. Box 808, Livermore, CA 94550

44. Q Division Library, Los Alamos Scientific Laboratory, P.0. Box 1663, Los Alamos, NM 87544

45. Controlled. Thermonuclear Research Library, c/o Weston M. Stacey, Jr., Argonne National Laboratory, 9700 S. Cass Ave., Argonne, IL. 60439

46. CTR Computer Center, c/o Dr. John Killeen, Lawrence Livermore Laboratory, P.0. Box 808, Livermore, CA 94550

47. Librarian, Culham Laboratory, U.K. Atomic Energy Authority, Abingdon, Oxon, 0x14 3DB, United Kingdom

48. Ruth Lengye, Bibliothek, Max-Planck Institut für Plasmaphysik, 8046 Garching bei München, Federal Repub1ic of Germany

49. Library, Centre de Recherches en Physique des Plasmas, 21 Avenue des Bains, 1007, Lausanne, Switzerland

50. A. M. Dupas, Documentation S.I.G.N., Department de la Physique du Plasma et de la Fusion Controlée, Association EURATOM-CEA sur la Fusion, Centre d'Etudes Nucleaires, BP 85 Centre Du TRI 38041 Grenoble Cedex (France)

51. Bibliotheque, Service du Confinement des Plasmas, C.E.A., B.P. No. 6, 92, Fontenay-aux-Roses (Seine) France

52. Library, International Centre for Theoretical Physics, Trieste, Italy

53. Library, Laboratorio Gas Ionizzati, Frascati, Italy

54. V. E. Ivanov, Physical-Technical Institute of the Ukranian Academy of Sciences, Sukhumi, U.S.S.R.

55. L. M. Kovrizhnikh, Lebedev Institute of Physics, Academy of Sciences of the U.S.S.R., Leninsky Prospect 53, Moscow, U.S.S.R.

56. Prof. Dshumber G. Lominadze, Academy of Sciences of the Georgian SSR, 8 Dzerzhinski St., 38004, Tbilisi, U.S.S.R.

57. Library, Inst. for Plasma Physics, Nagoya Univ., Nagoya, Japan 464 
58. Library, FOM-Institut voor Plasma-Fysica, Rijnhuizen, Jutphaas, Netherlands

59. Plasma Physics Group, Department of Engineering Physics, Australian National University, P.0. Box 4, Canberra A.C.T. 2600, Australia

60. Thermonuclear Library, Japan Atomic Energy Research Institute, Tokai, Naka, Ibaraki, Japan

61. Dr. D. G. McAlees, Exxon Nuclear.Co., Inc., Research \& Technology Laser Enrichment Department, 2955 George Washington Way, Richland, WA 99352

62. CTR Reading Room, c/o Prof. D. W. Kerst, Dept. of Physics, Sterling Ha11, Univ. of Wisconsin, Madison, WI 53706

63. CTR Reading Room, C/o Prof. I. B. Bernstein, Yale Univ., 200 Mason Laboratory, Dept. of Engineering \& Applied Science, New Haven, CT 06510

64. Center for Plasma Physics and Thermonuclear Research, C/O D. W. Ross, Physics Dept., Univ. of Texas, Austin, TX 78712

65. CTR Reading Room, c/O Prof. B. D. Fried, Physics Dept., Univ. of California, Los Angeles, CA 90024

66. CTR Reading Room, c/o Prof. David C. Montgomery, Physics \& Astronomy Dept., Univ. of Iowa, Iowa City, IA 52240

67. Magneto-Fluid-Dynamics Library, c/o Dr. Harold Grad, Courant Inst. of Math. Sci., New York Univ., 251 Mercer St., New York, NY 10012

68. CTR Reading Room, c/o Prof. Allan N. Kaufman, Physics Dept., Univ. of California, Berkeley, CA 94720

69. Dr. David A. Dingee, Fusion Programs; Battelle-Northwest, Battelle Boulevard, Richland, WA 99352

70. CTR Reading Room, c/o Prof. C. S. Liu, Dept. of Physics and Astronomy, Univ. of Maryland, College Park, MD 20742

71. CTR Reading Room, c/o Prof. T. Kammash, 103 Research Admin. B1dg., N. Campus, Univ. of Michigan, Ann Arbor, MI 48105

72. CTR Reading Room, c/o Dr. Ravi N. Sudan, Phillips Hall, Cornell Univ., Ithaca, NY 14850

73. Prof. Marshali N. Rosenbluth, Institute for Advanced Study, Princeton, NJ 08540

74. CTR Reading Room, c/o Prof. R. Gross, Plasma Research Lab., Columbia Univ., New York, NY 10027

75. CTR Reading Room, c/o Prof. Roy Gould, California Inst. of Tech., M.S. 116-81, Pasadena, CA 91125

76. Dr. Nicholas A. Kral1, Science Applications, Inc., P.0. Box 2354, 1200 Prospect St., La Jolla, CA 92037

77. CTR Reading Room, C/O Dr. Jay P. Boris, Plasma Physics, Naval Research Laboratory, Washington, D.C. 20390

78. Professor A. Simon, Dept. of Mechanic.al \& Aerospace Sctences, Unfversity of Rochester, Rochester, NY 14627

79. CTR Library, c/o Dr. Alan F. Haught, United Technologies Research Labs, East Hartford, CT 06108

80. Dr. H. K. Forsen, Exxon Nuclear Co., Inc., 777-106th Avenue, NE, C-000777, Bellevie, WA 98009

81. Dr. George Vahala, Physics Dept., College of William \& Mary, Williamsburg, VA 23185

82. Dr. Robert E. Price, Division of Magnetic Fusion Energy, G-234, Energy Research and Development Administration, Washington, D.C. 20545 
83. Dr. R. C. Davidson, Division of Magnetic Fusion Energy, G-234, Energy Research and Development Administration, Washington, D.C. 20545

84. Dr. Oscar P. Manley, Division of Magnetic Fusion Energy, G-234, Energy Research and Development Administration, Washington, D.C. 20545

85. Mr. E. E. Kintner, Division of Magnetic Fusion Energy, G-234, Energy Research and Development Administration, Washington, D.C. 20545

86. Dr. L. D. Pearlstein, L-388, Lawrence Livermore Laboratory, P.0. Box 808, Livermore, CA 94550

87. Dr. J. P. Friedberg, Los Alamos Scientific Laboratory, Los Alamos, NM 87.544

88. Dr. David J. Rose, Dept. of Nuclear Engineering, MIT, Cambridge, MA 02139

89. Dr. Gareth E. Guest, General Atomic Co., P.0. Box 81608, San Diego, CA 92138

90. Dr. Claude Mercier, Service du Theorie des Plasmas, Centre d'Etudes Nucleaires, Fontenay-aux-Roses (Seine) France

91. Dr. J. B. Taylor, Culham Laboratory, UKAEA, Abingdon, Oxon, OX14 3DB, United Kingdom

92. Dr. D. Pfirsch, Institute for Plasma Physics, 8046 Garching bei München, Federal Republic of Germany

93. Dr. V. D. Shafranov, I. V. Kurchatov Inst. of Atomic Energy, 46 Ulitsa Kurchatova, P.0. Box 3402, Moscow, U.S.S.R.

94. Dr. A. Rogister, Institute for Plasma Physics, KFA, Postfach 1913, D-5170, Jülich 1,. Federal Republic of Germany

95. Dr. J. G. Cordey, Culham Laboratory, UKAEA, Abingdon, Oxon, 0x14 3DB, United Kingdom

96. Dr. David Baldwin, L-388, Lawrence Livermore Lab., P.0. Box 808, Livermore, CA 94550

97. CTR Reading Room, c/o Prof. Bruno Coppi, Dept. of Physics, MIT, Cambridge, MA 02138

98. Dr. Harold P. Furth, Princeton Plasma Physics Lab., Princeton Univ., P.0. Box 451, Princeton, NJ 08540

99. Dr. Paul H. Rutherford, Princeton Plasma Physics Lab., Princeton Univ., P.0. Box 451, Princeton, NJ 08540

100. Research \& Technical Support Div., Oak Ridge Operations, Energy Research and Development Administration, P.O. Box E, Oak Ridge, TN 37830

101-127. Tech. Information Center, P. O. Box 62, Oak Ridge, TN 37830 